\title{
Hipertireoidismo felino
}

\author{
Feline hyperthyroidism
}

\section{Marina Gabriela Monteiro Carvalho Mori da Cunha ${ }^{\mathrm{I} *}$ Ney Luis Pippi ${ }^{\mathrm{II}}$ Kleber Gomes Diego Vilibaldo Beckmann ${ }^{\mathrm{I}}$}

\section{- REVISÃO BIBLIOGRÁFICA -}

\section{RESUMO}

O hipertireoidismo é considerado a endocrinopatia mais comum em felinos de meia idade a idosos, nos Estados Unidos e na Europa. No entanto, ainda existem poucos casos relatados no Brasil. O diagnóstico precoce e o tratamento adequado tornam o prognóstico do animal mais favorável, podendo até se obter a cura do paciente. Devido à importância desta afecção em felinos, são abordados, nesta revisão, os aspectos clínicos, diagnósticos e terapêuticos do hipertireoidismo felino.

Palavras-chave: endocrinopatia, tireóide, gato.

\section{ABSTRACT}

Hyperthyroidism is the most common endocrinopathy of middle aged and older cats in the United States and Europe, however there are few related cases in Brazil yet. The early diagnosis and the correct treatment become the prognosis more favorable, leading to patient cure. This paper reviews the clinical, diagnosis and therapeutic aspects of feline hyperthyroidism.

Key words: endocrinopathy, thyroid, cat.

\section{INTRODUÇÃO}

Hipertireoidismo é um quadro clínico resultante da excessiva produção e secreção de tiroxina (T4) e triiodotironina (T3) pela glândula tireóide. O hipertireoidismo em gatos é quase sempre causado por uma disfunção autonômica da tireóide e raramente por uma alteração no hipotálamo ou na hipófise (FELDMAN \& NELSON, 1996). Essa endocrinopatia resulta, em mais de $80 \%$ dos casos, em bócio, que é o aumento da glândula tireóide (PETERSON, 2006). A maioria dos casos de hipertireoidismo é causada pelo adenoma tireóideo ou pela hiperplasia adenomatosa multinodular, afetando um ou, mais comumente, ambos os lobos da glândula tireóide. Menos de 2\% dos casos ocorrem como resultado de carcinoma tireóideo funcional (LURYE, 2006; BIRCHARD, 2006).

O hipertireoidismo é a endocrinopatia mais comum em gatos nos Estados Unidos e na Europa (LURYE, 2006; BIRCHARD, 2006), afetando, aproximadamente, um em cada 300 gatos (GEBER et al., 1994). Houve uma maior incidência de hipertireoidismo nos últimos anos, sendo que esta foi maior do que outras duas enfermidades comuns de felinos (insuficiência renal crônica e diabetes melito). É improvável que este aumento esteja relacionado ao desenvolvimento de novos testes diagnósticos e ao maior atendimento de pacientes felinos, pois a prevalência continua aumentando, mesmo sem nenhum avanço substancial em testes diagnósticos (MOONEY, 2002; EDINBORO et al., 2004).

Há apenas um relato de caso desta doença publicado em periódico no Brasil (CARLOS \& ALBUQUERQUE, 2005) e alguns relatos em anais de congressos (HAIPEK et al., 2004; CUNHA et al., 2007). Acredita-se que essa baixa incidência de casos

'Programa de Pós-graduação em Medicina Veterinária, Universidade Federal de Santa Maria (UFSM), 97105-900, Santa Maria, RS, Brasil. E-mail: morimv@yahoo.com.br.*Autor para correspondência.

IIDepartamento de Clínica de Pequenos Animais, Centro de Ciências Rurais (CCR), UFSM, Santa Maria, RS, Brasil. 
diagnosticados esteja relacionada ao aumento recente da população felina nos centros urbanos, à baixa procura pelos serviços médico-veterinários e ao pouco conhecimento, dessa doença em felinos no Brasil.

O objetivo deste trabalho foi revisar os aspectos clínico, diagnóstico e terapêutico do hipertireoidismo em felinos e alertar os médicos veterinários sobre a potencialidade desta doença se tornar freqüente na rotina clìnica veterinária.

Anatomia

As glândulas tireóides são estruturas pares, alongadas e vermelho-escuras, fixadas na porção proximal da traquéia, caudalmente à laringe (PADGETT, 2002). Nos gatos adultos, elas têm $2 \mathrm{~cm}$ de comprimento e $0,3 \mathrm{~cm}$ de largura, mas são palpadas apenas quando aumentadas de tamanho (FERGUSON \& FREEDMAN, 2006). As glândulas paratireóides externas situam-se na superfície craniolateral da tireóide e podem ser distinguidas pela sua coloração mais clara e pelo seu formato arredondado (BIRCHARD, 2006).

Um tecido tireóideo acessório funcional é comum ao longo da traquéia, do mediastino e da porção torácica da aorta descendente e por isso não ocorre hipotireoidismo quando se realiza a tireoidectomia bilateral (BIRCHARD, 1984). Uma pequena percentagem de gatos possui tecido paratireóideo ectópico no mediastino anterior, porém este tecido não é capaz de manter os níveis de calcemia normais imediatamente após a paratireoidectomia (NAAN et al., 2006).

\section{Predisposição e patogenia}

A alteração ocorre em gatos entre quatro e 22 anos, sendo que 95\% dos felinos acometidos têm mais de 10 anos de idade (FELDMAN \& NELSON, 1996). No entanto, já existe relato desta endocrinopatia em filhote de oito meses (GORDON et al., 2003). Não há predileção por raça ou sexo, embora alguns estudos tenham evidenciado que gatos Himalaios e Siameses são menos predispostos (KASS et al., 1999).

A patogenia dessa doença ainda não está bem definida, entretanto, pressupõe-se que fatores circulatórios (imunoglobulinas), nutricionais (iodo na dieta) e ambientais (toxinas bociogênicas) possam influenciar em sua patogênese, pois em 70\% dos casos há um aumento bilateral da glândula tireóide apesar de não haver conexão entre os dois lobos tireoidianos (LURYE, 2006).

Estudos concluíram que gatos que se alimentam de ração enlatada e aqueles que usam granulado sanitário têm um aumento significativo no risco de desenvolver hipertireoidismo (MARTIN et al.; 2000; EDINBORO et al., 2004). Devido à associação desta enfermidade com a dieta, foram desenvolvidas pesquisas que consideraram o iodo como sendo a causa da progressão da doença. A concentração de iodo contido na comida enlatada é extremamente variável, estando freqüentemente com nível até 10 vezes maior do que aquele recomendado (MOONEY, 2002).

Outra possível causa para o desenvolvimento de lesão adenomatosa são os produtos usados no revestimento das latas, que utiliza o bisfenol em seu processo. Estes compostos são metabolizados por glucoronidação para sua eliminação e esse metabolismo é particularmente lento na espécie felina (MOONEY, 2002; EDINBORO et al., 2004).

\section{Sinais clínicos}

As alterações clínicas de hipertireoidismo são progressivas e mais da metade dos gatos apresentam essas alterações em seis meses a um ano antes de serem encaminhados ao veterinário. Isso ocorre devido à apresentação clínica inicial (aumento do apetite e hiperatividade) ser confundida com um estado saudável (FELDMAN \& NELSON, 1996). Este retardo em diagnosticar a tireopatia pode levar o animal a apresentar um estágio avançado dessa doença (Figura 1).

A maioria dos sinais clínicos ocorre devido a uma taxa metabólica basal acelerada, com aumento do consumo de oxigênio pelos tecidos, e elevada sensibilidade às catecolaminas pelo aumento do número e da afinidade aos receptores betaadrenérgicos na superfície celular (FELDMAN \& NELSON, 1996; CARDOSO et al., 2005). Aapresentação clínica clássica inclui taquicardia, hiperatividade, emaciação progressiva, polifagia, diarréia, êmese, poliúria e polidipsia (GUNN-MOORE, 2005; BIRCHARD, 2006).

O estado hipermetabólico resulta em um aumento da contração e do consumo do oxigênio pelo miocárdio, do débito cardíaco e do gasto de energia, levando a uma hipertrofia cardíaca compensatória (SALISBURY, 1991). Na ausculta cardíaca pode-se evidenciar taquicardia, ritmo de galope, sopro sistólico e arritmia (PETERSON et al., 1983), que, após a correção do estado hipertireóideo, normalmente regridem (OLSON, 2001).

O aumento da pressão arterial sistólica ocorre em $87 \%$ dos casos e as prováveis causas dessa manifestação são as combinações do estado hiperdinâmico do coração, a retenção de sódio, os baixos níveis de vasodilatadores renais, a perda de 


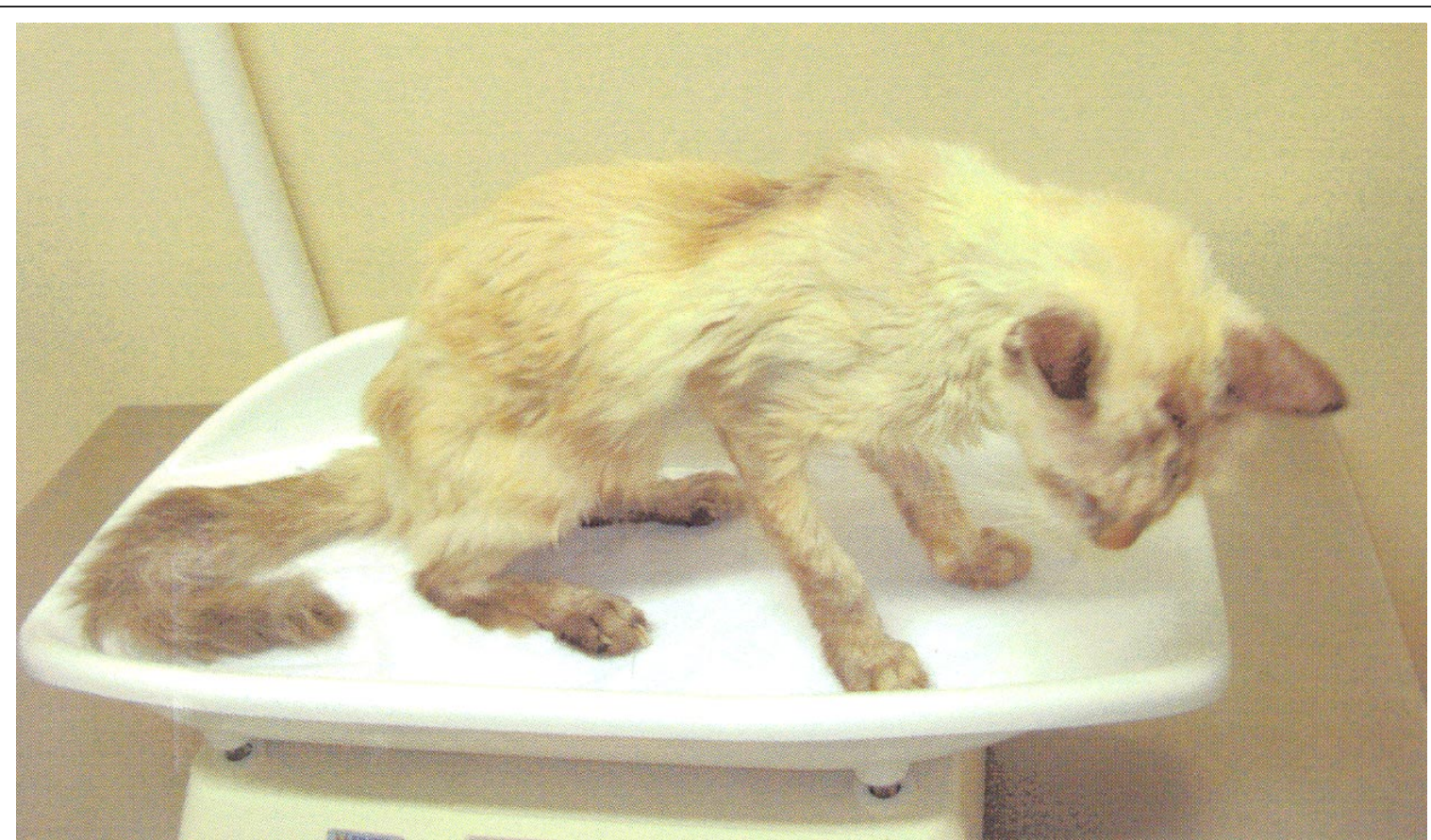

Figura 1 - Aspecto físico de felino, com doze anos de idade, em estágio avançado de hipertireoidismo. Notar a extrema caquexia e a ventroflexão cervical.

autoregulação da pressão sangüínea glomerular e a ativação do sistema renina-angiotensina-aldosterona (OLSON, 2001). A hipertensão não é resolvida de imediato após a normalização de T4 total e quando esta for de moderada a severa pode ser tratada com atenolol, amlodipina ou algum inibidor da enzima conversora de angiotensina até que a pressão arterial normalize (TREPANIER, 2006).

A perda de peso ocorre em $90 \%$ dos casos e é secundária ao aumento do metabolismo basal, que requer maior demanda calórica e acarreta em uma ingestão maior de alimentos, levando à polifagia (FELDMAN \& NELSON, 1996; CARDOSO et al., 2005).

Em casos avançados, pode ocorrer anorexia, devido à severa perda de peso, fraqueza e perda de massa muscular pelo catabolismo protéico (FELDMAN \& NELSON, 1996).

O aumento da freqüência de defecação e a diarréia são secundários à hipermotilidade intestinal, à polifagia e à má absorção, sendo geralmente acompanhados de esteatorréia (PETERSON et al., 1983). O vômito pode resultar da ação direta do hormônio tireóideo na zona quimiorreceptora bulbar ("zona de gatilho”) ou da distensão gástrica aguda, decorrente da grande quantidade de alimento ingerida rapidamente (FELDMAN \& NELSON, 1996).

O hipertireoidismo aumenta a taxa de filtração glomerular, podendo ocorrer poliúria e polidipsia que mascararam uma insuficiência renal crônica (IRC) concomitante (LANGSTON \& REINE, 2006). MAYER-ROENNE et al. (2007) relataram que o hipertireoidismo predispõe o desenvolvimento de infecção do trato urinário (ITU). Provavelmente não exista envolvimento da IRC em sua patogênese, pois não há uma relação da ITU com a proteinúria e tampouco com a baixa densidade urinária.

A astenia muscular, que ocorre em menos de $15 \%$ dos casos, pode ocorrer devido à hipocalemia e/ou à deficiência de tiamina (vitamina B1) que são induzidas pela tireotoxicose (FELDMAN \& NELSON, 1996). A hipocalemia, presente em $32 \%$ dos gatos hipertireóideos, ocorre devido à elevação dos hormônios da tireóide e à liberação de catecolaminas, estimulando o movimento do potássio do espaço extracelular para o intracelular (NAAN et al., 2006).

Problemas dermatológicos ocorrem em $40 \%$ dos gatos, podendo apresentar alopecia pelo excesso de lambedura e/ou à avulsão pilar, devido à intolerância ao calor ou pêlos emaranhados em razão da ausência de auto-higienização, em casos de apatia (FELDMAN \& NELSON, 1996) (Figura 2a).

\section{Diagnóstico}

Deve-se investigar a ocorrência de hipertireoidismo em todos os felinos de meia idade ou idosos que apresentem histórico de perda de peso, 


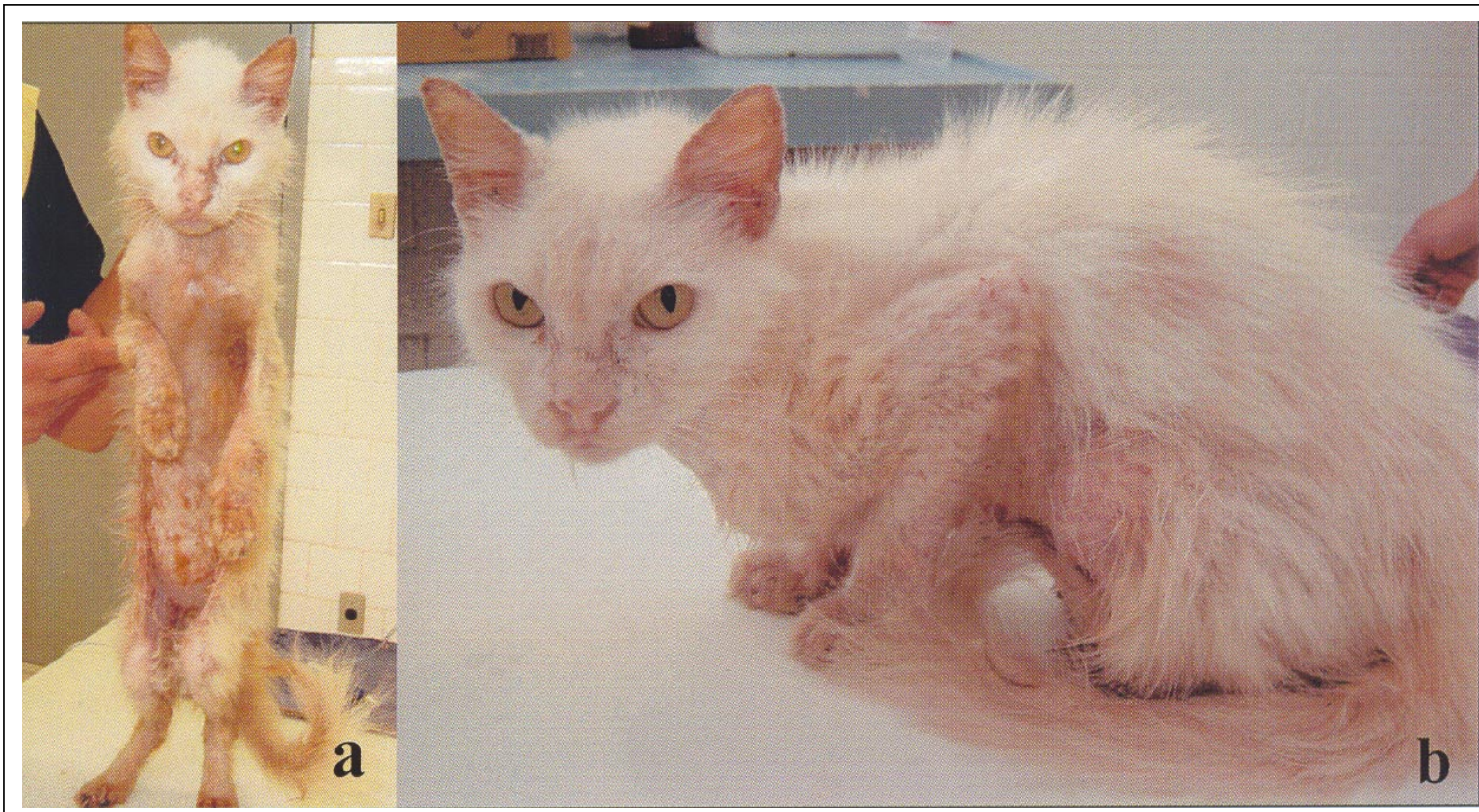

Figura 2 - Aspecto físico de felino hipertireóideo, com onze anos de idade. Notar a alopecia ventral devido à lambedura excessiva e à avulsão pilar (a), e a emaciação, a apatia e a pelagem eriçada (b).

principalmente quando evidenciar polifagia. O exame físico geralmente revela uma má condição clínica, uma pelagem opaca e um aumento da glândula tireóide (GUNN-MOORE, 2005) (Figura 2b).

Deve-se palpar a tireóide sempre que houver suspeita dessa afecção. Caso o nódulo não seja evidenciado inicialmente, pode-se mudar a posição da cabeça e palpar duas a três vezes em cada lado, deslizandose os dedos lateralmente à traquéia (FERGUSON \& FREEDMAN, 2006). NORSWORTHY et al. (2002a) caracterizaram as glândulas tireóides por tamanho, sendo zero quando não palpável, e um, dois, três, quatro, cinco e seis, as glândulas palpáveis com 0,5cm; 0,75cm;1,0cm; $1,5 \mathrm{~cm} ; 2,0 \mathrm{~cm}$ e $2,5 \mathrm{~cm}$, respectivamente. Esses mesmos autores relataram a ocorrência de aumento do hormônio tiroxina a partir do escore quatro. FERGUSON \& FREEDMAN (2006) recomendaram fazer acompanhamento semestralmente em gatos com lobos classificados em um, dois ou três e tratamento do hipertireoidismo com lobos classificados acima de quatro.

O achado de um ou mais lobos tireóideos aumentados no exame físico não pode definir se o animal é hipertireóideo, pois o aumento da tireóide ocasionalmente pode ser encontrado em gatos sem alterações clínicas e sem evidência laboratorial da doença (NORSWORTHY et al., 2002b). Apesar de alguns gatos com aumento da tireóide permanecerem eutireóideos por longos períodos de tempo, muitos eventualmente desenvolvem o hipertireoidismo (PETERSON, 2006).

\section{Exames laboratoriais}

A alteração hematológica mais freqüente é a eritrocitose, ocorrendo em $47 \%$ dos gatos hipertireóideos. Essa alteração é ocasionada pelo elevado consumo de oxigênio e pelo estímulo ßadrenérgico sobre a medula óssea, elevando a eritropoese (MOONEY, 2001).

O aumento das enzimas hepáticas (Alaninaaminotransferase, Fosfatase alcalina e Gamaglutamiltransferase) ocorre em $90 \%$ dos casos. No entanto, estas retornam para os valores de referência após o tratamento. Esse aumento ocorre provavelmente em decorrência da má nutrição, da insuficiência cardíaca congestiva, da anóxia hepática e do efeito tóxico direto dos hormônios tireoidianos no fígado (MOONEY, 2001).

Freqüentemente, evidencia-se azotemia e hiperfosfatemia nesses pacientes (PETERSON et al., 1983). Nenhuma nefropatia específica é atribuída ao hipertireoidismo. No entanto, acredita-se que o aumento da pressão do capilar glomerular e da proteinúria em gatos com hipertireoidismo possa contribuir para a progressão da doença renal (LANGSTON \& REINE, 2006).

\section{Diagnóstico definitivo}

O diagnóstico de hipertireoidismo é normalmente realizado usando-se a combinação de sinais clínicos, palpação da tireóide, testes laboratoriais ou de imagem (PETERSON, 2006). 
A mensuração de T4 total é comumente a mais utilizada para confirmar o diagnóstico de hipertireoidismo (MOONEY, 1996, PETERSON et al., 2001). Quando o seu valor está aumentado, o resultado é extremamente específico para o diagnóstico de hipertireoidismo (PETERSON, 2006). Noentanto, um resultado dentro da normalidade não permitirá que se descarte o hipertireoidismo, uma vez que podem ocorrer flutuações circadianas dos valores séricos de T3 e T4 ou diminuição nas concentrações de T4 total no soro decorrentes de enfermidades concomitantes não tireoidianas, tais como nefropatia, diabete melito, neoplasia, hepatopatia e outras afecções crônicas (SALISBURY, 1991; PETERSON et al., 2001).

A determinação de T4 livre por diálise é um teste diagnóstico bastante útil em gatos com grande suspeita de hipertireoidismo e concentração de T4 total dentro dos valores de referência. É importante salientar que somente a alta concentração de T4 livre não pode determinar o diagnóstico definitivo, já que entre 6 e $12 \%$ dos casos pode haver falso positivo devido à alta sensibilidade deste (MOONEY, 1996; PETERSON et al., 2001). A mensuração de T4 livre deverá ser avaliada sempre em conjunto com T4 total para evitar tais falsos positivos (PETERSON, 2006). Um valor de T4 total médio a ligeiramente elevado associado ao valor elevado de T4 livre é consistente com hipertireoidismo, mas um T4 total baixo associado ao valor elevado de T4 livre é associado à doença não-tireoidiana (MOONEY, 2001).

O hipertireoidismo deve ser considerado em gatos com insuficiência renal crônica (IRC) e bócio que estejam apresentando T4 total e T4 livre no limite superior dos valores de referência, pois a IRC pode suprimir a concentração de hormônio tiroxina, podendo resultar em uma inabilidade de diagnosticar quadros de hipertireoidismo leve a moderado (LANGSTON \& REINE, 2006).

O mapeamento da tireóide com radionucleotídeo (Tecnécio-99) fornece uma fotografia de todo o tecido tireóideo funcional, permitindo o delineamento e a localização de áreas da tireóide funcional e não-funcional (MOONEY, 2001; PETERSON, 2006). Tal exame é utilizado em gatos com apresentação clínica compatível com hipertireoidismo e concentrações séricas de T4 normais e para identificar presença de tecido tireóideo ectópico em gatos com sinais clínicos de hipertireoidismo e hipertiroxinemia, mas com ausência de nódulos palpáveis (MOONEY, 2001). Este método diagnóstico é considerado o melhor meio de contraste de imagem de emprego na rotina diagnóstica dessa enfermidade em gatos (PETERSON, 2006), porém tem uso limitado devido ao alto custo e à necessidade de um equipamento computadorizado sofisticado (MOONEY, 2001; PETERSON, 2006).

\section{Tratamento}

A terapia deve ser individualizada, levando em conta vários fatores, tais como idade, severidade da tireotoxicose, presença de doença concomitante, potenciais complicações, custo e aceitação do tratamento pelo proprietário (MOONEY, 2001).

Existem três opções de tratamento para o hipertireoidismo: uso do iodo radioativo, de fármacos antitireoidianos e procedimento cirúrgico (TREPANIER, 2006).

Antes de um tratamento definitivo em gatos hipertireóideos acometidos por doença renal, deve-se tentar o tratamento medicamentoso, pois poderá ocorrer a desestabilização do animal devido à diminuição da taxa de filtração glomerular, podendo desencadear uma descompensação da IRC (LANGSTON \& REINE, 2006; NAAN et al., 2006). A manutenção de eutireoidismo por um mês, sem azotemia, pode ser suficiente para decidir por uma terapia definitiva (LANGSTON \& REINE, 2006).

\section{Iodo radioativo}

O iodo 131 é o radionucleotídeo de escolha para o tratamento de hipertireoidismo causado por tumores funcionais da tireóide, sendo também uma boa opção para lobos tireóideos bastantes aumentados bilateralmente, para gatos com massas tireóideas ectópicas hiperfuncionais e em casos de carcinoma de tireóide (MOONEY, 1996). Ele é administrado por via intravenosa, concentrando-se na tireóide, e destruindo células foliculares funcionais sem lesar estruturas adjacentes. $\mathrm{O}$ inconveniente desse tratamento é que ele se limita a locais específicos licenciados, além de ser a opção mais cara e necessitar de hospitalização prolongada (SALISBURY, 1991). A cura do paciente ocorre em $80 \%$ dos casos, $10 \%$ não respondem ao tratamento e $10 \%$ desenvolvem hipotireoidismo(GUNN-MOORE, 2005).

Fármacos antitireoidianos

A terapia com fármacos antitireóides possui as vantagens de não ser necessária anestesia geral, ser a opção mais barata e não requerer hospitalização. O inconveniente dessa terapia é que ela necessita de administração da medicação continuamente e de monitoração constante dos hormônios tireoidianos, além de não ocasionar a diminuição do bócio e, freqüentemente, ocorrer efeitos colaterais (NORSWORTHY, 1995).

Os fármacos antitireoidianos disponíveis (propiltiouracil, metimazol, carbimazole) pertencem à classe das tionamidas (MOONEY, 2001). Estes inibem 
a síntese do hormônio da tireóide, porém, devido ao fato de não haver efeito antitumoral, a glândula tireóide continua aumentando de volume (SALISBURY, 1991). O propiltiouracil é o mais potente, mas possui efeitos colaterais mais sérios. O fármaco mais usado atualmente é o metimazole (MOONEY, 2001). Este deve ser iniciado em doses baixas, de 1,25 a 2,5mg duas vezes ao dia, para verificar se a concentração de T4 poderá ser seguramente normalizada sem causar descompensação renal (TREPANIER, 2006). Após, pode-se aumentar a dose para $5 \mathrm{mg}$ duas a três vezes ao dia, dependendo da severidade da tireotoxicose (MOONEY, 2001).

Avaliações mensais devem ser realizadas durante os três primeiros meses, pois esse é o período em que os efeitos colaterais normalmente ocorrem (SALISBURY, 1991). Os efeitos colaterais desencadeados pelo metimazole ocorrem em $18 \%$ dos casos e incluem discrasias sangüíneas, escoriação facial e hepatoxicidade. Nesses casos realiza-se a descontinuação do tratamento medicamentoso e preconiza-se outra forma de tratamento (TREPANIER, 2006). Outros efeitos colaterais menos severos são letargia, vômito e anorexia, que ocorrem em 15\% dos gatos, e geralmente desaparecem com o uso contínuo da droga. Uma opção à administração oral é o metimazole transdermal, que é associado com menor efeito gastrintestinal e pode ser usado em gatos com vômito ou inapetência devido à irritação gástrica desencadeada pelo metimazole (HOFFMANN et al., 2003).

Alterações hematológicas discretas, tais como eosinofilia, linfocitose e leucopenia ocorrem em $10 \%$ dos gatos e alterações menos comuns, porém mais sérias, incluem trombocitopenia, neutropenia e anemia hemolítica. Hepatotoxicidade ocorre um em pequeno número de gatos (2\%), sendo que nesses casos indicase a descontinuação do metimazole e o início de terapia de apoio. Após uma semana da descontinuação desse fármaco, as enzimas hepáticas retornam ao seu valor de referência. No entanto, é comum a recidiva com o reinício do tratamento (TREPANIER, 2006).

\section{Cirúrgico}

A tireoidectomia é uma opção efetiva de tratamento para gatos com hipertireoidismo, pois oferece cura permanente sem tratamento medicamentoso contínuo, além de não necessitar de equipamento especializado (BIRCHARD, 2006). Esta pode ser realizada com uma baixa incidência de complicações quando realizada por um cirurgião experiente. Para tanto, utiliza-se um protocolo anestésico com mínimo efeito cardiovascular adverso ao paciente e realiza-se a estabilização pré-operatória, a fim corrigir principalmente a hipocalemia e as alterações cardíacas (NAAN et al., 2006).

Gatos severamente afetados devem ser tratados no pré-operatório com metimazole com o intuito de estabilizar o animal, diminuindo os riscos cirúrgicos (SALISBURY, 1991). Após duas a quatro semanas de tratamento, deve-se dosar novamente a concentração de T4 total e, se este estiver normalizado, o procedimento cirúrgico é então realizado (BIRCHARD, 2006). Se o tratamento com fármaco antitireóide não for tolerado, agentes bloqueadores beta-adrenérgicos (propanolol e atenolol) podem ser utilizados para estabilizar o paciente (NAAN et al., 2006).

Agentes anticolinérgicos são contraindicados para evitar taquicardia e arritmia (FLANDERS, 1999), assim como a cloridrato de cetamina para que não haja estimulação simpática e liberação de catecolaminas (SALISBURY, 1991). Recomenda-se o uso de acepromazina $0,1 \mathrm{mg} . \mathrm{kg}-1$, por via intramuscular, com a finalidade de diminuir o tono autonômico nesses pacientes, reduzindo assim as chances de ocorrer arritmias (PADGETT et al., 2002).

Diferentes técnicas de tireoidectomia têm sido desenvolvidas com o intuito de minimizar potenciais complicações pós-operatórias associadas à tiroidectomia bilateral, como a hipocalcemia e a recorrência do hipertireoidismo. Esta recorrênica pode ocorrer até meses após a tireoidectomia se tecido tireóideo adenomatoso permanecer no local (FLANDERS, 1999) ou se existir tecido tireóideo ectópico (NAAN et al., 2006).

A técnica de tireoidectomia intracapsular é efetuada mediante incisão da cápsula tireóidea e remoção de todo o tecido da tireóide. A cápsula permanece no animal com a glândula paratireóide externa aderida (BIRCHARD et al., 1984). Essa técnica tem a vantagem de proteger a paratireóide, mas aumenta a possibilidade de deixar tecido tireóideo anormal no gato, havendo assim recidiva do hipertireoidismo (PADGETT et al., 2002).

A técnica de tireoidectomia extracapsular é realizada mediante cuidadosa dissecação da glândula paratireóide externa da cápsula tireóidea com o cuidado de manter intacta a vascularização da paratireóide (PADGETT et al., 2002). Essa técnica tem menor probabilidade de deixar tecido tireóideo anormal no gato porque a cápsula tireóidea não é invadida, porém há um maior risco de desencadeamento de hipoparatireodismo. Isso ocorre porque os vasos paratireóideos podem ser facilmente seccionados ou lesados devido à manipulação dos tecidos (FLANDERS, 1999).

NORSWORTHY (1995) citou a técnica de tireoidectomia extracapsular bilateral com transplante de 
paratireóide em duas etapas, como uma alternativa para evitar as complicações cirúrgicas dessas técnicas. Nesta técnica, a glândula paratireóide é implantada no ventre muscular do esterno-hióideo, após a remoção extracapsular da glândula tireóide. A revascularização ocorre em média aos 14 dias do transplante da paratireóide. No entanto, recomenda-se uma nova intervenção somente após três semanas depois da primeira cirurgia (PADGETT et al., 1998). Essa é a técnica mais vantajosa, pois não necessita de demorada dissecação da vasculatura tiróidea e evita a hipocalcemia, pois permite que haja a revascularização ipsilateral do tecido paratireóideo antes da glândula tireóide contralateral ser removida e seu suprimento sangüíneo ser potencialmente interrompido (FLANDERS, 1999). Sua maior desvantagem é a necessidade de dois procedimentos cirúrgicos (BIRCHARD, 2006).

Após a extirpação cirúrgica da glândula, esta deve ser sempre encaminhada para análise histopatológica, devido à possibilidade deste tumor ser um carcinoma, em que o prognóstico e a terapia serão diferentes (MOONEY, 1996).

Potenciais complicações da tireoidectomia incluem mudança na vocalização, síndrome de Horner, paralisia da laringe e hipoparatireoidismo em casos de tireoidectomia bilateral em que houve desvascularização, ou remoção inadvertida de toda a paratireóide (BIRCHARD et al., 1984; LURYE, 2006). A taxa de recorrência é baixa e ocorre principalmente devido à existência de tecido tireóideo ectópico hiperplásico (NAAN et al., 2006).

A avaliação do cálcio sérico deve ser realizada após 18 a 24 horas da tireoidectomia bilateral, não sendo essencial em casos de procedimento unilateral ou bilateral associado ao reimplante da glândula paratireóide em duas etapas, pois apenas uma glândula paratireóide é suficiente para manter a normocalcemia (FLANDERS, 1999). Normalmente a hipocalcemia ocorre dentro das primeiras 24 horas (PADGETT et al., 1998). Entretanto a dosagem da concentração do cálcio sérico deve ser feita por no mínimo dois dias de pós-operatório (BIRCHARD, 2006).

Alterações clínicas precoces de hipocalcemia incluem letargia, anorexia, relutância em se mover, fasciculações fasciais (principalmente das orelhas), tremores musculares, tetania e convulsões (BIRCHARD, 2006). O hipoparatireoidismo pela completa desvascularização da glândula paratireóide é resolvido em 14 dias. Se passar desse tempo, é provável que tenha ocorrido a completa paratireoidectomia (FLANDERS, 1999).

A suplementação com cálcio deve ser instituída em casos de sinais clínicos de hipocalcemia ou quando a concentração de cálcio sérico estiver abaixo de $7 \mathrm{mg} \mathrm{dl}^{-1}$ (FLANDERS, 1999; BIRCHARD, 2006). Inicialmente, deve-se administrar 1 a $1,5 \mathrm{ml} \mathrm{kg}^{-1}$ de gluconato de cálcio a $10 \%$ lentamente por via intravenosa, tendo o cuidado de interromper a administração se ocorrer bradicardia. Em seguida, devese administrar $2 \mathrm{ml} \mathrm{kg}^{-1}$ da mesma solução por infusão contínua nas próximas oito horas ou por via subcutânea diluída em solução fisiológica (1:1) (MOONEY, 1996). Não deve-se administrá-lo com solução de bicarbonato de sódio, pois haverá precipitação (BIRCHARD, 2006). Assim que houver estabilização do paciente, deve-se iniciar a medicação oral na dose de 50 a $75 \mathrm{mg} \mathrm{kg}^{-1}$ dia $^{-1}$ divididos em três a quatro doses e $0,03 \mathrm{mg} \mathrm{kg}^{-1} \mathrm{dia}^{-1} \mathrm{de}$ dihidrotaquisterol. Quando o paciente obtiver a normocalcemia, pode-se diminuir a dose deste para $0,01 \mathrm{mg} \mathrm{kg}^{-1}$ a cada dois dias, até que ocorra a normocalcemia (MOONEY, 1996).

Os níveis de T4 total devem ser avaliados após um mês da tireoidectomia para constatar que todo o tecido tireóideo anormal foi retirado e que a glândula contralateral não está afetada (BIRCHARD, 2006). Quinze por cento dos casos de hipertireoidismo bilaterais apresentam um dos lobos aparentemente normal no momento da cirurgia. Nesses casos a terapia com metimazole deverá ser reintroduzida e, assim que houver a estabilização do paciente, a tireoidectomia contralateral poderá ser realizada (MOONEY, 1996).

Prognóstico

O prognóstico depende da condição física do animal na época do diagnóstico, da coexistência de doenças concomitantes, da característica histológica da massa, da terapia adequada de acordo com a condição física do animal e da localização das massas hiperfuncionantes. Felinos hipertireóideos sem tratamento geralmente têm um prognóstico desfavorável, devido à predisposição às doenças concomitantes, tais como nefropatias, cardiomiopatias, hepatopatias e hipertensão sistêmica (GUNN-MOORE, 2005).

Gatos tratados mostram mudança comportamental e um significativo ganho de peso, apresentando normalmente prognóstico favorável (GUNN-MOORE, 2005; BIRCHARD, 2006). Mais de $30 \%$ de gatos não-azotêmicos desenvolvem azotemia associada com a IRC após o tratamento de hipertireoidismo, no entanto, a azotemia tende a ser média e estável por longos períodos (LANGSTON \& REINE, 2006).

\section{CONCLUSÃO}

Assim como ocorreu em alguns países, é previsível que os casos de hipertireoidismo felino no 
Brasil passem a aumentar significativamente. Os clínicos veterinários devem dedicar maior atenção aos sinais clínicos iniciais dessa doença, uma vez que o diagnóstico precoce e o tratamento adequado tornam o prognóstico do animal mais favorável, podendo até se obter a cura do paciente, sem nenhuma seqüela remanescente.

\section{REFERÊNCIAS}

BIRCHARD, S.J. et al. Surgical treatment of feline hyperthyroidism. Journal of the American Animal Hospital Association, v.20, n.5, p.705-709, 1984.

BIRCHARD, S.J. Thyroidectomy in the cat. Clinical Techniques in Small Animal Practice, v.21, n.1, p.29-33, 2006.

CARDOSO, M.J.L. et al. Manifestações clínicas em gatos com hipertireoidismo experimental. Archives of Veterinary Science, v.10, n.2, p.135-144, 2005.

CARLOS, R.S.A.; ALBUQUERQUE, G.R. Hipertireoidismo felino: relato de caso. Revista Clínica Veterinária, n.57, p.56-61, 2005.

CUNHA, M.G.M.C.M. Tireoidectomia extracapsular associada ao Transplante da glândula paratireóide em um felino. Acta Scientiae Veterinariae, v.35, s.2, p.s468-s469, 2007. Trabalho apresentado no Congresso Brasileiro da ANCLIVEPA, 28., 2007, Florianópolis.

EDINBORO, C.H. et al. Epidemiologic study of relationships between consuption of commercial canned food and risk of hyperthyroidism in cats. Journal of American Veterinary Medical Association, v.224, n.6, p.879-886, 2004.

FELDMAN, E.C.; NELSON, R.W. Feline hyperthyroidism (Thyrotoxicosis). In: ____. Canine and feline endocrinology and reproduction. Philadelphia: Saunders, 1996. Cap.4, p.118-165.

FERGUSON, D.C.; FREEDMAN, R. Goiter in apparently euthyroid cats. In: AUGUST, J.R. Consultations in feline internal medicine. Missouri: Elsevier Saunders, 2006. Cap.23, p.207-215.

FLANDERS, J.A. Surgical options for the treatment of hyperthyroidism in the cat. Journal of Feline Medicine and Surgery, v.1, n.3, p.127-134, 1999.

GERBER, H. et al. Etiopathology of feline toxic nodular goiter Veterinary Clinics of North America: Small Animal Practice, v.24, n.3, p.541-565, 1994.

GORDON, J.M. et al. Juvenile hyperthyroidism in a cat. Journal of the American Animal Hospital Association, v.39, n.1, p.67-71, 2003.

GUNN-MOORE, D. Feline endocrinopathies. Veterinary Clinics of North America: Small Animal Practice, v.35, n.1, p.171-210, 2005.

HAIPEK, K. et al. Hipertireoidismo em felinos: 08 casos (19972003). In: CONGRESSO BRASILEIRO DE CLÍNICOS VE-
TERINÁRIOS DE PEQUENOS ANIMAIS, 25., 2004, Gramado. Revista da ANCLIVEPA Brasil. Rio de Janeiro: Régis Comunicação e Marketing. Suplem, p.51, 2004.

HOFFMANN, G. et al. Transdermal methimazole treatment in cats with hyperthyroidism. Journal of Feline Medicine and Surgery, v.5, n.2, p.77-82, 2003.

KASS, P.H. et al. Evaluation of environmental, nutritional, and host factors in cats with hyperthyroidism. Journal of Veterinary Internal Medicine, v.13, n.4, p.323-329, 1999.

LANGSTON, C.E.; REINE, N.J. Hyperthyroidism and the kidney. Clinical Techniques in Small Animal Practice, v.21, n.1, p.17-21, 2006.

LURYE, J.C. Update on treatment of hyperthyroidism. In: AUGUST, J.R. Consultations in feline internal medicine. Missouri: Elsevier Saunders, 2006. Cap.22, p.199-205.

MARTIN, K.M. et al. Evaluation of dietary and environmental risk factors for hyperthyroidism in cats. Journal of American Veterinary Medical Association, v.217, n.6, p.853-856, 2000 .

MAYER-ROENNE, B. et al. Urinary tract infections in cats with hyperthyroidism, diabetes mellitus and chronic kidney disease. Journal of Feline Medicine and Surgery, v.9, n.2, p.124-132, 2007.

MOONEY, C. Decision making in the treatment for hyperthyoidism in cats. In Practice, v.18, n.4, p.150-156, 1996.

MOONEY, C.T. Feline hyperthyroidism: diagnostics and therapeutics. Veterinary Clinics of North America: Small Animal Practice, v.31, n.5, p.963-983, 2001.

MOONEY, C.T. Pathogenesis of feline hyperthyroidism. Journal of Feline Medicine and Surgery, v.4, n.3, p.167169, 2002

NAAN, E.C. et al. Results of thyroidectomy in 101 cats with hyperthyroidism. Veterinary Surgery, v.35, n.3, p.287-293, 2006.

NORSWORTHY, G.D. Feline thyroidectomy: a simplified technique that preserves parathyroid function. Veterinary Medicine, v.90, n.11, p.1055-1063, 1995.

NORSWORTHY, G.D. et al. Relationship between semiquantitative thyroid palpation and total thyroxine concentration in cats with and without hyperthyroidism. Journal of Feline Medicine and Surgery, v.4, n.3, p.139-143, 2002a.

NORSWORTHY, G.D. et al. Palpable thyroid and parathyroid nodules in asymptomatic cats. Journal of Feline Medicine and Surgery, v.4, n.3, p.145-151, 2002b.

OLSON, J.K. Hyperthyroidism. In: LAPPIN, M.R. Feline internal medicine secrets. 2.ed. Philadelphia: Hanley \& Belfus, 2001. Cap.53, p.383-387.

PADGETT, S.L. et al. Efficacy of parathyroid gland autotransplantation in maintaining serum calcium concentrations after bilateral thyroparathyroidectomy in cats. 
Journal of the American Animal Hospital Association, v.34, n.3, p.219-224, 1998.

PADGETT, S.L. et al. Feline thyroid surgery. Veterinary Clinics of North America: Small Animal Practice, v.32, n.4, p.851-859, 2002.

PETERSON, M.E. et al. Feline hyperthyroidism: pretreatment clinical and laboratory evaluation of 131 cases. Journal of the American Veterinary Medical Association, v.183, n.1, p.103-110, 1983.

PETERSON, M.E. et al. Measurement of serum concentrations of free thyroxine, total thyroxine and total triiodothyronine in cats with nonthyroidal disease. Journal of American Veterinary Medical Association, v.218, n.4, p.529-536, 2001.

PETERSON, M.E. Diagnostic tests for hyperthyroidism in cats. Clinical Techniques in Small Animal Practice, v.21, n.1, p.2-9, 2006.

SALISBURY, S.K. Hyperthyroidism in cats. The Compendium Collection, v.13, n.9, p.172-178, 1991.

TREPANIER, L.A. Medical management of hyperthyroidism. Clinical Techniques in Small Animal Practice, v.21, n.1, p.22-28, 2006. 